\title{
INTERRATIONAL COOPERATIVE EFFORT TO ESTABLISH DOSIMETRY STANDARDIZATION FOR RADIATION PROCESSING
}

\author{
Harry Farrar IV
}

Rockwell International Corporation, Canoga Park, California 91303 USA

\section{Rockwell International}

\author{
AP04-88A253385
}

\section{DISCLAIMER}

This report was prepared as an account of work sponsored by an agency of the United States Government. Neither the United States Government nor any agency thereof, nor any of their employees, makes any warranty, express or implied, or assumes any legal liability or responsibility for the accuracy, completeness, or usefulness of any information, apparatus, product, or process disclosed, or represents that its use would not infringe privately owned rights. Reference herein to any specific commercial product, process, or service by trade name, trademark, manufacturer, or otherwise does not necessarily constitute or imply its endorsement, recommendation, or favoring by the United States Government or any agency thereof. The views and opinions of authors expresed herein do not necessarily state or reflect those of the United States Government or any agency thereof.

Paper to be presented at the 7 th International Meeting on Radiation Processing, Leeuwenhorst Congres Center, Noordwijkerhout, The Netherlands, April 23-28, 1989 
INTERNATIONAL COOPERATIVE EFFORT TO ESTABLISH DOSIMETRY STANDARDIZATION FOR RADIATION PROCESSING

\author{
Harry Farrar IV
}

Rockweli International Corporation Canoga Park, California 91303 USA

\begin{abstract}
Radiation processing is a rapidly developing technology with numerous applications in food treatment, sterilization, and polymer modification. The effectiveness of the process depends, however, on the proper application of dose and its measurement. These aspects are being considered by a wide group of experts from around the world who have joined together to write a comprehensive set of standards for dosimetry for radiation processing.

Originally formed in 1984 to develop standards for food processing dosimetry. the group has now expanded into a full subcomittee of the American Society for Testing and Materials (ASTM), with 97 members from 19 countries. The scope of the standards now includes Josimetry for all forms of radiation processing.

The group has now completed and published four standards, and is working on an additional seven. Thrfe are specifically for food applications and the others are for all radiation applications, including food processing. Together, this set of standards will specify acceptable guidelines and methods for accomplishing the required irradiation treatment, and will be available for adoption by national regulatory agencies in their procedures and protocols.
\end{abstract}

\title{
INTRODUCTION
}

The control and measurement of absorbed radiation dose is of paramount importance to assure the quality of the irradiated product and to assure regulatory compliance. In general, regulatory authorities require the processor to control the irradiation process so that all parts of the product receive an absorbed dose within certain prescribed limits. The required dose range will depend on the product and the desired effect, such as extended shelf-life or insect disinfestation for food, or sterilization for medical products. The lower limit must be high enough to accomplish this desired effect but the higher limit should not be so high as to cause adverse affects. Therefore, adequate dosimetry with proper statistical controls and documentation is necessary to assure the products are appropriately treated.

For irradiation treatments to be reproducible in the laboratory and then in the comercial environment, and for products to have certified absorbed doses, standardiced dosimetry techniques are essential. A number of different standards are necessary because of the very different types of facilities (experimental, ganma ray, electron beam, $x-r a y$, etc.), and the wide variety of dosimetry systems available. Different dosineters are needed for different applications because of orders of magnitude differences in dose required for different products, differences in absorbed doses resulting from irradiating products of different densities, etc. No single dosimeter can fulfill the full range of requirements. suine of the more accurate dosimeters are rather cumbersome or expensive, and some are more sensitive to temperature, humidity, storage time, or rough handing. All these characteristics are covered in a set of standards and guidelines being developed under the auspices of ASTM. These include guidelines on how to select dosimeters, standards on where to put them, how often lo use them, and how many to use. Also being developed are standards on how to calibrate and use a gamma or electron beam irradiation facility for food processing, standards on precisely how to use individual types of dosimeters for any applications, and a standard on how to treat dosimetry uncertainties.

\section{ASTM}

ASTM is an international organization founded in 1898. It is the world's largest source of voluntary consensus standards, with more than 32,000 members belonging to approximately 2000 subcomittees. The organization covers a wide range of subjects, with over 8,000 standards for materials, products, systems and services ranging from shipbuliding alloys. 
plastics, paint, construction, and deodorants to textiles, energy, biotechnology, and robotics. ASTM publishes their current standards and procedures annually in 67 volumes. In 1986, 26\% of all ASTM publications were sold outside the United States, and over 10\% of ASTh mernbers are from outside the United States.

Individual ASTM standards are established by task groups consisting of both members and nonmembers, including anyone who wants to participate. This of ten includes people from industry, government, manufacturers, regulatory agencies, universities, cald consumer groups. For a long time, ASTM has actively encouraged participation in the working groups from overseas experts, and ASTM has recently been in contact with other similar standards-setting organizations overseas to coordinate standardizing activities.

Anyone may contribute to the writing of the standards, may vote and use a veto. The results of this process are standards, guidelines, and procedures that represent the latest state-of-the-art thinking, and that have the unanimous support of all interested parties. This makes the standards of particular value for specifying how research or production operations should be done properly. The standards are also ideally suited for adoption by government regulators for inclusion in treatment, process, or quarantine protocols.

\section{SUBCOMMITTEE ON DOSIMETRY FOR RADIATION PROCESSING}

Subcommittee E10.01, "Dosimetry for Radiation Processing," started out in 1984 as a task group to develop standards for dosimetry for food processing as a part of committee E.10 on Nuclear Technology and Applications. Since then, it has become a full subcommittee with an expanded goal of producing standards applicable to all types of radiaxion processing. The group has a steadily increasing membership of active participants and contributors.

Table 1 gives a breakdown of the affiliations for the 97 members, representing 19 countries on four continents. Fifty-seven of the members have attended one or more of the ten 3-day subcomittee meetings held since 1984 .

Table 1. ASIM Subcommittee E10.01

Membership Affiliations

\begin{tabular}{lr}
\hline Government-sponsored R\&D laboratories & 22 \\
Regulatory agencies & 15 \\
Calibration laboratories & 9 \\
Irradiator manufacturers & 11 \\
Dosimeter manufacturers & 5 \\
Irradiation operators---medical industry & 9 \\
Irradiation operators--food industry & 7 \\
Food industry & 5 \\
Commercial radiation services & 6 \\
Irradiation consultants & 4 \\
Universities & 8 \\
Total membership (19 countries) & 97 \\
\hline
\end{tabular}

The general scope of the activities of the subcomittee is to establish and maintain standards and guidelines for dosimetry in ionizing radiation processing including processing of medical products, pharmaceuticals, foods, polymers, and other consumer products. In addition, the scope includes developing methodologies for characterizing and operating garma-ray, $x$-ray, and electron beam irradiators, and encouraging use of these standards and guidelines in radiation processing through meetings, workshops, and symposia. The rirst symposium to be sporisored by Subcomittee El0.01 will be an international workshop on dosimetry for radiation processing on Octoberl-6, 1989, in Ste-Adele, Quebec, Carlada.

\section{STATUS OF STANDAROS}

Four of the standards being developed by Subcommittee E10.01 have been released for publication. Two are test methods: $t 1275$ for radiochromic film dosimetry systems and E7276 for polymethylmethacrylate (PMMA) dosimetry systems. The other two are for food applirations: E1261 for selecting and applying dosjmetry systems for radiation processing of food and E1204 for the application of dosimetry $N_{d}$ the characterization and operation of a gamma irradiation facility for food processing. These will be published in volume 12.02 of the Annual Book of ASTM Standards, along with three other standards developed earlier by a sister ASTM Subcommittee E10.07, El066 for calculating absorbed dose from 
gamma or X-radiation, E668 for thermoluminescence dosimetry (TLD) systems, and E1026 for the Fricke dosimeter.

Seven additional standards are in various stages of completion. Three are tegf methods describing the use of radiochromic optical waveguide, dichromate, and alaningdosimetry systems, respectively. A fourth is a guide for the use of radiacion-sensitive indicatars. A fifth standard is for dosimetry in an electron and Brefinsstrahlung irradiation facility for food processing, and a sixth is for the performance of a gamma radiation dosimetry calibration laboratory for industrial testing and processing. The seventh is a guide for the estimation and application of dosimetric uncertainties in the process control of gamma and electron irradiation facilities. Together, when these are all complete, the set will be published as a separate Standard Technical Publication (STP).

\section{PARTICIPATION IN SUBCOMMITIEE E10.01}

It is easy for any individual to join Subcommittee E10.01. The only requirement is that each member must contribute in some way to the development of the standards. Joining ASTM, which costs $\$ 50$ a year, is not necessary, but it does allow the task group member to vote. It is essential, however, that each member provide comments on the drafts of the standards in a timely fashion. This can be done by writing or by telephone, but the best way is by attending the semi-annual subcomittee meetings. It is the synergistic interaction between the members, where each can hear the other viewpoints, that results in useful and rapid progress. Recent meetings have been attended by 25-30 participants. A special meeting of the subcommittee is being held in Noordwijkerhout. The Hetherlands, during the 7 th International Meeting on Radiation Processing, and the next regular meeting will be held in Washington, $D C$, on June 14-16, 1989, adjacent to a meeting of the Association for the Advancement of Hedical Instrumentation, who share several of our members. Subsequent meetings are planned for Las Vegas in January 1990, Nashville in June 1990, and San Diego and Niagara Falls in 1991.

Given the numerous applications of irradiation and the prospects of increased international trade in irradiated products, including irradiated food, the need exists for detailed protocols and procedures concerning the treatinents. This has been recognized by ASTM Subcommittee E10.01, and the expectation is that the standards now being developed with cooperation from key individuals from so many countries will provide the lechnical basis for future specifications, laws, and protocols. 